\title{
Laser Beam Welding of Titanium Nitride Coated Titanium Using Pulse-Shaping
}

\author{
Milton Sergio Fernandes de Lima* \\ Laboratoire de Simulation des Matériaux, Swiss Federal Institute of Technology Lausanne, \\ CH-1015 Lausanne, Switzerland
}

Received: November 30, 2004; Revised: March 28, 2005

\begin{abstract}
A new welding method which allows the assembly of two titanium nitride coated titanium parts is proposed. The welding procedure utilizes the possibility for pulse-shaping in order to change the energy distribution profile during the laser pulse. The pulse-shaping is composed of three elements: a) a short high power pulse for partial ablation at the surface; b) a long pulse for thermal penetration; and c) a quenching slope for enhanced weldability. The combination of these three elements produces crack-free welds. The weld microstructure is changed in comparison to normal welding, i.e. with a rectangular pulse, as the nitrogen and the microhardness are more homogenously distributed in the weld under pulse-shaping conditions. This laser pulse dissolves the TiN layer and allows nitrogen to diffuse into the melt pool, also contributing to an enhanced weldability by providing suitable thermal conditions.
\end{abstract}

Keywords: laser beam welding, titanium, titanium nitride

\section{Introduction}

Titanium and its alloys have been used in a number of applications, for example in parts for aerospace use replacing steel and aluminum. Titanium possesses an excellent strength to weight ratio, good corrosion resistance and relatively high operational temperature. Some titanium alloys have replaced aluminum when the operation temperature is above $130{ }^{\circ} \mathrm{C}^{1}$, which is the maximum temperature for aluminum in engineering applications. Examples of titanium use are the external shells of turbines, the power units for avionics and the gear landing structural components in Boeings 747 and $757^{2}$. Even though the first choice for this last application was the 7000-class aluminum alloy (Al-Zn-Mg), which has lower density and lower production costs than titanium, a Ti-Al-V alloy was applied. For the same application, the dimensions of aluminum bars should be too large for the wings envelope and the steel bars will greater increase the total weight of the landing gear. The use of titanium in military aircrafts has also increased in the last years. As an example, some wing components of the F-15 (McDonnell Douglas) and structural parts of the F-22 (Lockheed Martin and Boeing) are made of titanium ${ }^{3}$.

However, major obstacles to a broad utilization of titanium as a structural material are linked to its low wear resistance. This problem has been overcome by applying a thin hard ceramic coating on the surface. The application of nitride or carbonitride coatings can promote effective resistance to abrasion and friction without changing the interesting bulk properties of titanium alloys ${ }^{4}$. Nitridation of metallic components is already an established industrial practice ${ }^{5}$, however some problems still remain concerning the assembly of coated parts.

The joining or repairing of previously coated parts is very difficult. Most nitrides present melting temperature above $3000{ }^{\circ} \mathrm{C}$ and thus behave as inclusions during normal welding service. These inclusions can induce crack initiation and parts failure as long as internal tensions are present. Therefore, the most common method consists of coating removal, repair and re-deposition. These steps are carried out in separate processes generating operational costs and low product lifetime. On the other hand, when the entire ensemble is welded, i.e. base titanium plus coating, metallurgical problems are encountered. Especially the welding of titanium nitride (TiN) coated titanium presents cracking due to the low toughness of nitride phase ${ }^{6}$.
Laser beam welding has been used to weld titanium structures in aerospace industry because of easy automation and low distortion due to very precise control of the heat input ${ }^{7}$. The precise heat input can also be employed to control the thermal transfer to the weld pool which, under specific process parameters, can eliminate cracking after welding.

Michaud et al. ${ }^{8}$ have proposed that temporal pulse shaping can reduce cracking in sensible high-strength aluminum alloys. The pulse shaping consists of changing the energy distribution of the laser pulse during its duration.

Here, it is proposed a pulse shaping aiming increase the weldability of TiN-coated $\mathrm{Ti}$ in respect to the cracking problem. The objective of the present work is to develop a process where titanium can be welded without the removal of the nitride coating.

\section{Experimental}

\subsection{Materials}

In this work, two commercial purity $(99,8 \%)$ titanium sheets with dimensions $30 \times 20 \times 2 \mathrm{~mm}$ were welded. One face of each sheet was coated with TiN using PDV (Physical Vapor Deposition) generating a hard coating of $2 \mu \mathrm{m}$ thickness. The TiN coating showed an elevated microhardness value $(\sim 2300 \mathrm{HV})$ and the titanium substrate showed a quite low value $(\sim 180 \mathrm{HV})$.

\subsection{Welding}

Spot welding of sheets was carried out in the butt-joint configuration with the TiN layer face to the laser beam. Here, only separate one-shot pulses were analyzed therefore any laser track was realized. Figure 1 presents a schematic representation of the process.

The laser was a Rofin-Sinar RSY-1000P model with maximum average power of $1.2 \mathrm{~kW}$ and wavelength of $1.06 \mu \mathrm{m}$. Beam delivery was assured by a $10 \mathrm{~m}$ long optical fiber $(600 \mu \mathrm{m}$ diameter $)$ attached to a focusing head with a focal length of $120 \mathrm{~mm}$. This laser allows change the temporal distribution of energy during the pulse through an optional parameter called pulse shaping. Conventional lasers produce pulses which are approximately rectangular, meaning that 
the amount of energy is constant during the pulse duration. Here, the pulse shaping can be engineered to produce special heating and cooling regimes in order to control the weld thermal cycle. Figure 2 presents a schematic picture of the temporal evolution of laser pulse in a given pulse shaping and in normal conditions.

The conditions for welding at normal conditions, rectangular pulse, were determined in order to produce a weld bead of about $1 \mathrm{~mm}$ depth. After, the original rectangular pulse is changed to reproduce a pulse with high-peak energy at starting and a controlled quenching slope at the end, similarly to the picture presented in Figure 2. The average peak power $(\mathrm{P})$ is maintained approximately constant for both cases, rectangular and pulse-shapped energy distribution. It is worthwhile to say that no further attempts were made in order to produce some process optimization. The welding conditions are presented in Table 1.

Another series of experiments were carried out by defocusing the laser beam by $6 \mathrm{~mm}$ inside the material.

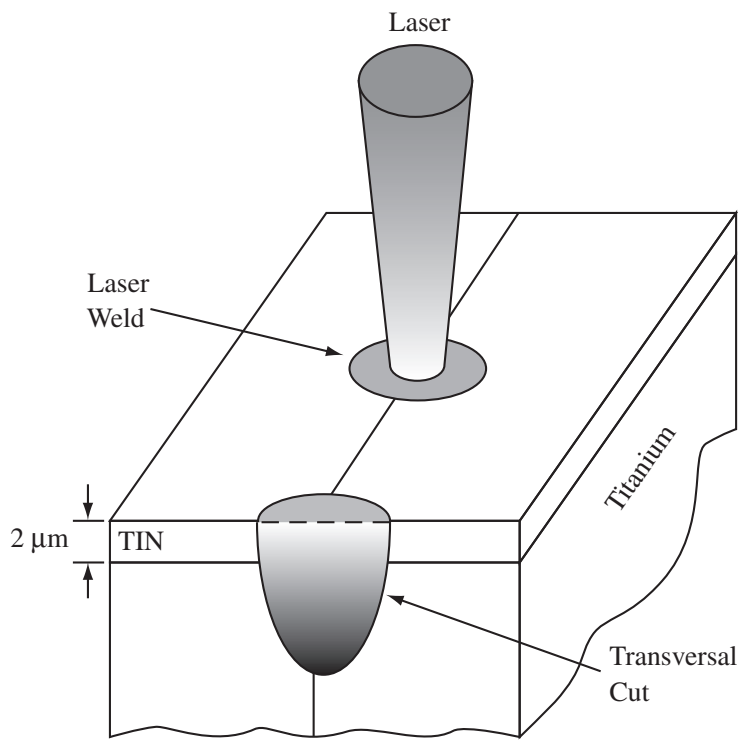

Figure 1. Schematic drawing of the spot welding with a pulsed laser.

\subsection{Characterization}

The metallographic analyses were carried out using optical and scanning electron microscopy with attached EDS (Energy-dispersive $\mathrm{X}$-ray Spectrometry) for punctual chemical analyses. Using a sample of stoichiometric $\mathrm{TiN}(50 \% \mathrm{~mol} \mathrm{~N})$ as standard, these chemical analyses were utilized to determine the nitrogen content in the weld. The average nitrogen amount was evaluated within an area of $100 \mu \mathrm{m}^{2}$.

The standard was necessary because the lines of $\mathrm{N}$ are near the beginning of the scanning spectrum and also due to possible overlap between $\mathrm{N}$ and Ti lines. A specific algorithm had been used to process the spectra taking atomic absorption into account.

Optical and scanning electron micrographs were obtained after transversal cuts (Figure 1) followed by chemical etching with Kroll's reagent (92 $\mathrm{ml}$ distilled water, $6 \mathrm{ml}$ nitric acid, $2 \mathrm{ml}$ fluoridric acid). Vicker's microhardness tests were carried out in different positions of the weld bead, which will be further discussed here. For these tests the weight was $100 \mathrm{~g}$ and the dwell time was $8 \mathrm{~s}$. Each microhardness result was an average of four consecutive tests in the nearest regions.

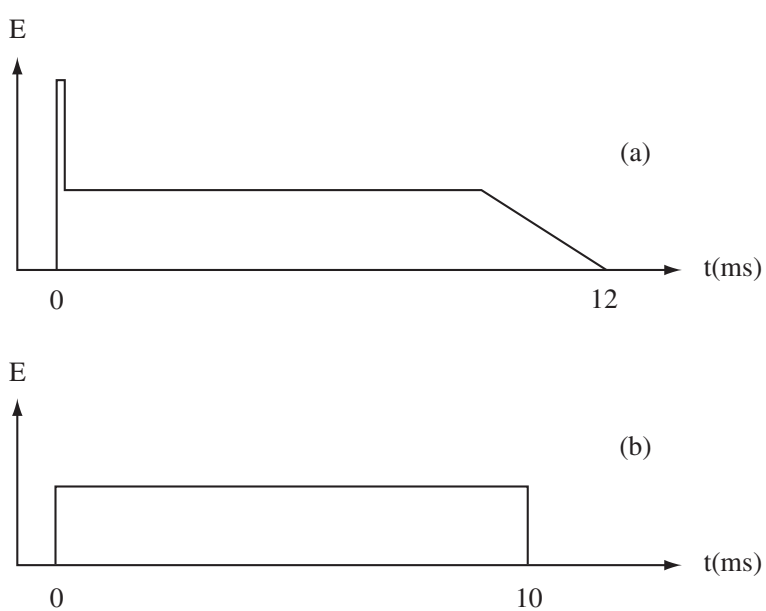

Figure 2. Schematic laser energy profiles during a pulse under a) pulse shaping; and b) normal conditions.

Table 1. Experimental conditions.

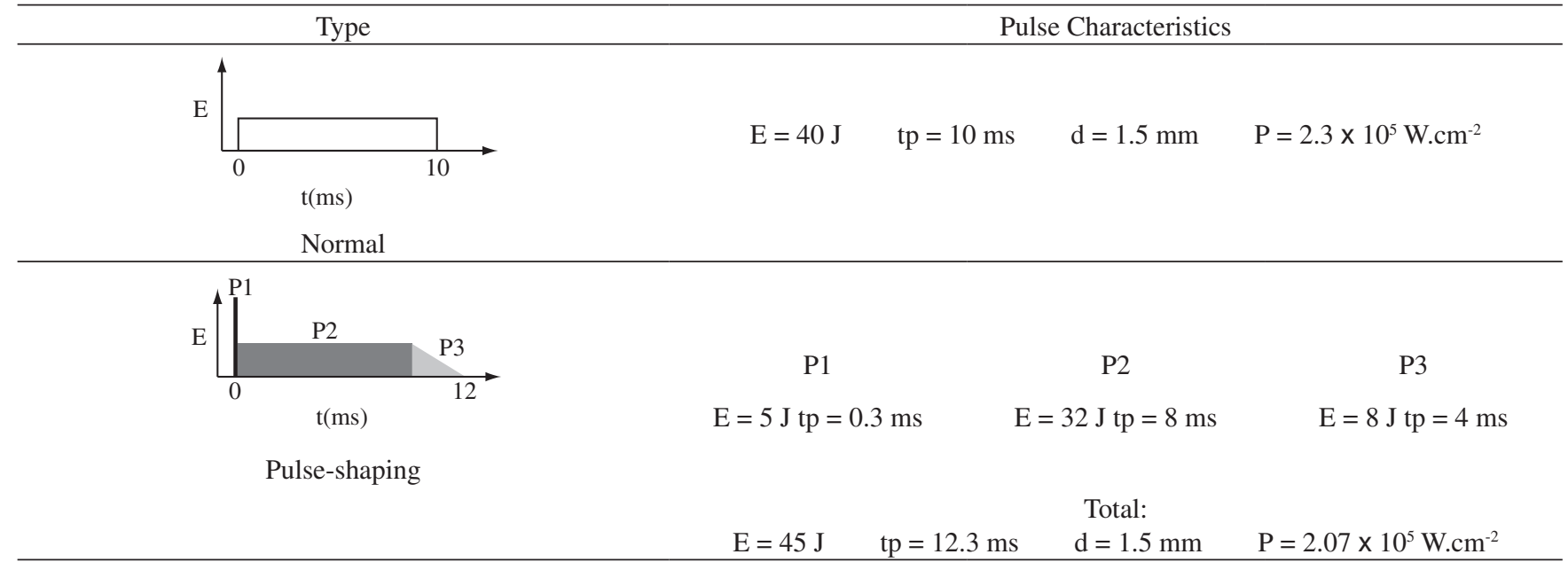

Legend: $\mathrm{E}=$ energy per pulse; $\mathrm{t}$ = pulse length; $\mathrm{d}=$ laser spot diameter; $\mathrm{P}=$ peak power. 


\section{Results}

\subsection{Engineering of the laser pulse}

First, the laser spot-welding under normal conditions, i.e. rectangular pulse format Figure 2b, was realized. As presented in Table 1, the total energy per pulse was $40 \mathrm{~J}$ during $10 \mathrm{~ms}$. The laser beam was defocused $3 \mathrm{~mm}$ into the part thus producing a $1.5 \mathrm{~mm}$ spot diameter at surface (measured using thermal paper). Therefore, the rectangular pulse had a intensity of $2.3 \times 10^{5} \mathrm{~W} \cdot \mathrm{cm}^{-2}$. Figure 3 a presents a transversal cut of a typical weld under these normal conditions. The weld depth is about $1 \mathrm{~mm}$ and the heat-affected zone extends to $1.3 \mathrm{~mm}$. The dark region on the top presents a crack approximately at the joining line. This crack is verified in most transversal cuts under this condition, after ten consecutive tests.

In the pulse shaping (PS) case, the total energy was $45 \mathrm{~J}$ and the pulse length was $12 \mathrm{~ms}$, as already presented in Table 1 . The pulse energy was distributed in three consecutive steps: 1$)$ a short $(0.3 \mathrm{~ms})$ and high-energy $(5 \mathrm{~J})$ pulse with intensity $\left.9.4 \times 10^{5} \mathrm{~W} . \mathrm{cm}^{-2}, 2\right)$ a thermal penetration regime similar to the normal pulse but with $32 \mathrm{~J}$ energy and $8 \mathrm{~ms}$ pulse duration, giving an intensity of $2.2 \times 10^{5} \mathrm{~W} \cdot \mathrm{cm}^{-2}$, and
3) a quenching profile until the end of the pulse with $4 \mathrm{~ms}$ pulse duration and $8 \mathrm{~J}$ energy. As stated before, these PS conditions were not optimized however the absence of cracks was the quality factor, since no cracks can be found in ten consecutive welds. Figure $3 \mathrm{~b}$ shows a transversal cut in this PS condition. The weld is crack-free and with similar penetration of the normal welds.

\subsection{Microstructure}

Looking to the Figure $3 \mathrm{a}$, it could be seen that the dark region is more concentrated at the top of the weld for normal weld conditions, and more homogeneously distributed in the case of a PS weld (Figure $3 \mathrm{~b}$ ). Figure 4 shows details in the dark region for both conditions, where nitrides (marked A) and martensite ( $\alpha$-phase, marked B) are visible. These phases were also visible at the middle of the weld and seemed to be better distributed in the pulse-shaping (PS) welding conditions.

In the middle regions, marked 2 in Figure 3, different microstructures were also verified between normal and PS conditions. Martensite plates and nitride particles were more refined in the PS weld, as can be seen by scanning electron microscopy, Figure 5 .

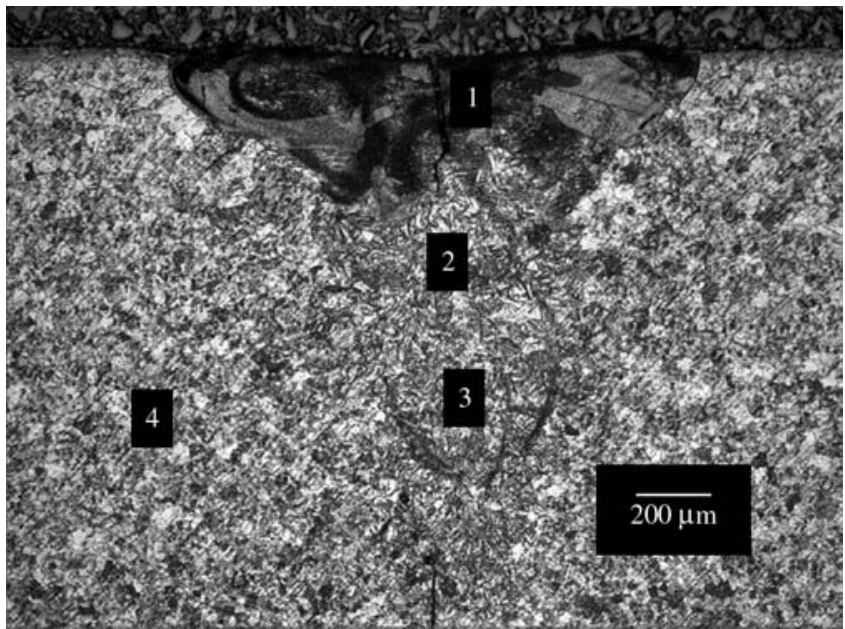

(a)

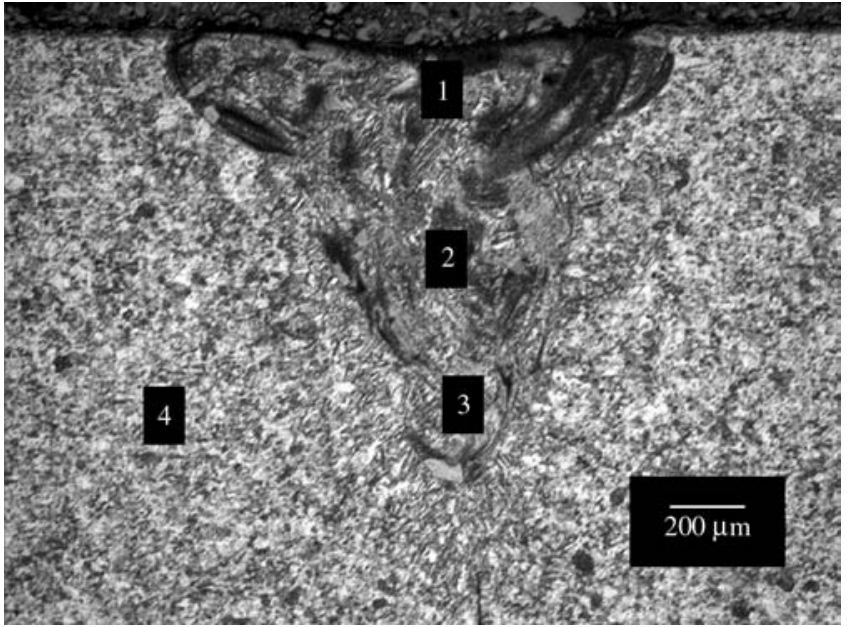

(b)

Figure 3. a) Transversal cut of the welding under a) normal; and b) optimized conditions. The numbers refer to the composition and microhardness tests.

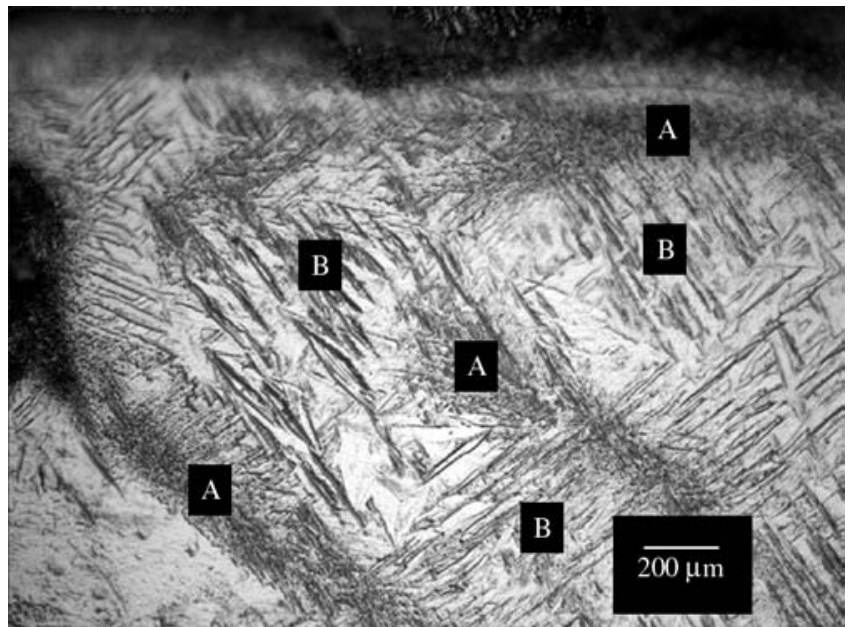

(a)

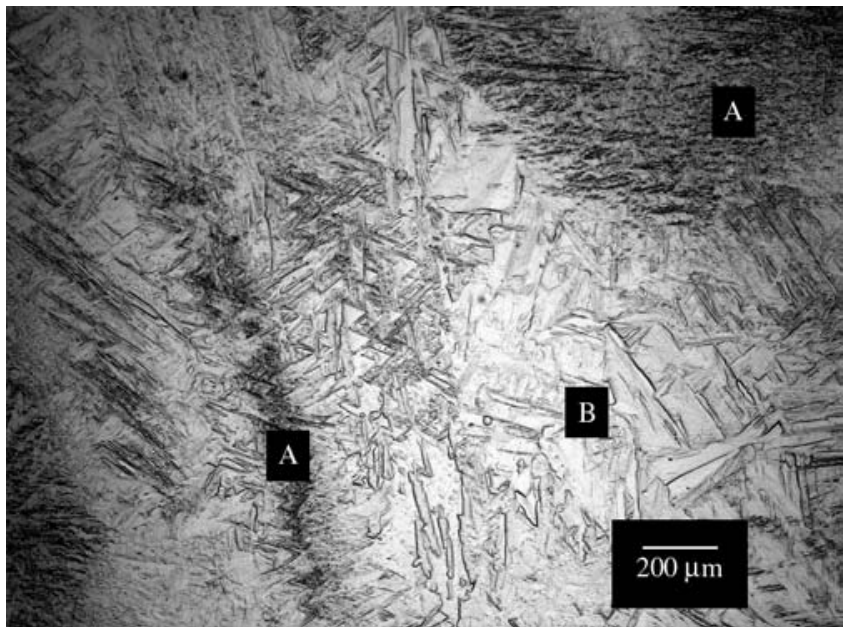

(b)

Figure 4. Details of the region near top: a) normal welding; and b) optimized welding. The zones marked A are rich in TiN and those marked B are mainly composed by titanium martensite. 


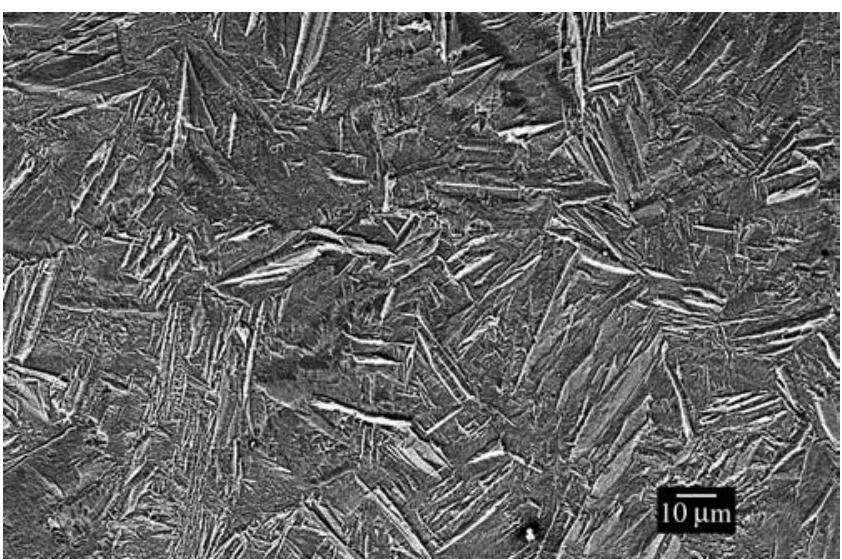

(a)

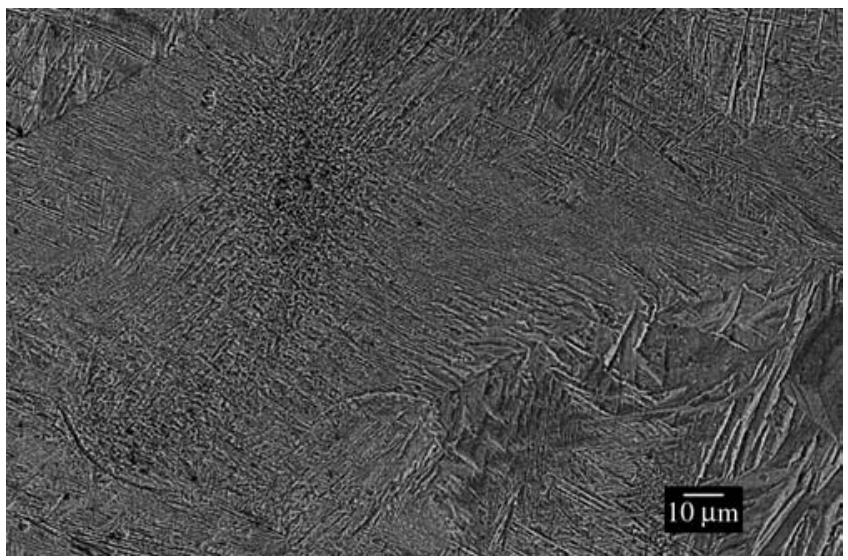

(b)

Figure 5. Micrographs at same scale from SEM showing central regions in welds obtained in a) normal; and b) optimized conditions.

Chemical analyses of the welded regions on the top and bottom, marked 1 and 3 in Figure 3, were obtained by EDS. The average nitrogen amounts are presented in Table 2 . The difference between top and bottom nitrogen composition was 6.2 and $0.9 \%$ for normal and PS welds, respectively.

\subsection{Microhardness}

Vicker's microhardness tests were realized in different regions marked by numbers 1 to 4 in Figures $3 \mathrm{a}$ and $3 \mathrm{~b}$. Table 3 presents the average measured values for a $100 \mathrm{~g}$ weight. The differences between top and bottom region hardnesses were 172 and $100 \mathrm{HV}$ for normal and PS conditions, respectively.

\subsection{Change of welding conditions}

In order to understand the mass transfer from the nitride coating to the weld pool, a experience was made where the laser beam was defocused $6 \mathrm{~mm}$ inside the material, i.e. the spot radius was increased, and the energy levels were kept constant. The pulse was under normal, rectangular shape, conditions. Figure 6 shows a transversal cut where the convection flux ${ }^{9}$ is evident. The nitrides at the weld top are dragged inside the weld first traveling to the weld pool boarder and then moving down. The numbers in Figure 6 are the average Vicker's microhardness.
Table 2. Nitrogen content analyses in welds (molar percentage).

\begin{tabular}{ccc}
\hline Region & Normal & Optimized \\
\hline (1) Top & 42.7 & 38.6 \\
(2) Center & 36.5 & 37.5 \\
\hline
\end{tabular}

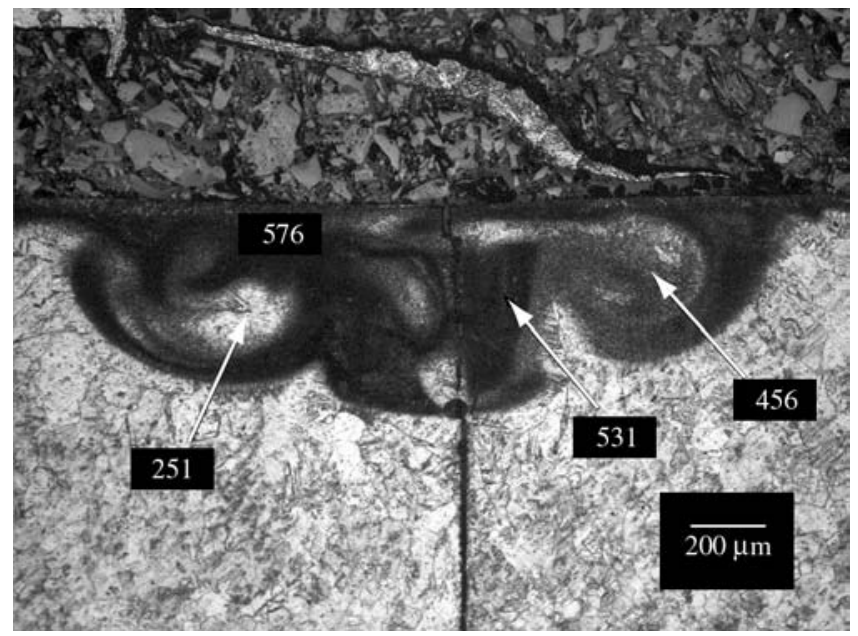

Figure 6. Normal conditions weld test with an expanded beam. The numbers refer to the average microhardness values.

The decrease of nitride phase content in the PS welds can be easily visualized when the weld pool is smaller. Two welds, under normal and PS conditions, when the total power is reduced by $30 \%$ are presented in Figure 7. It is observed that the dark phase is present everywhere in the normal weld. On the other hand, the dark phase is only observed at the boarders of the PS welding.

\section{Discussion}

The results indicate the effectiveness of the method of changing the pulse time format for enhanced weldability of TiN-coated titanium weldments. Here, the term weldability denotes the effectiveness to produce crack-free joins. It had been shown that the microstructure and the microhardness changes in the weld under pulse-shaping (PS) conditions. The PS method improves the transfer of nitrogen to the volume of the weld. Also the martensite plates are finer and better distributed using this method.

Under normal conditions, i.e. rectangular pulse, the laser heating is not sufficient to dissolve the TiN coating which is presented as a fine dispersion, inoculating the liquid with solid particles and creating the dark region visible in Figures $3 \mathrm{a}$ and $7 \mathrm{a}$. The convection flux stirred the nitride particles near to surface. As TiN solid has a slightly lower density than the liquid titanium, the nitride phase was concentrated at the surface.

In the new welding conditions, here called PS, the pulse promotes three processes: the dissolution of TiN coating by a short high-energy pulse, the penetration with a long pulse and the thermal gradient reduction through a quenching slope. These three processes can be separated for clearness.

First, the short $(0.3 \mathrm{~ms})$ pulse was sufficiently intense $\left(9.4 \times 10^{5} \mathrm{~W} . \mathrm{cm}^{-2}\right)$ to melt the Ti/TiN surface. In order to support this assumption, an experiment using only the part 1 (P1) in Table 1 was carried out. Figure 8, which is a scanning electron micrograph, shows a thin remelted layer near the sample surface. Then the nitrogen is dissociated from the TiN particles and absorbed by liquid titanium. 


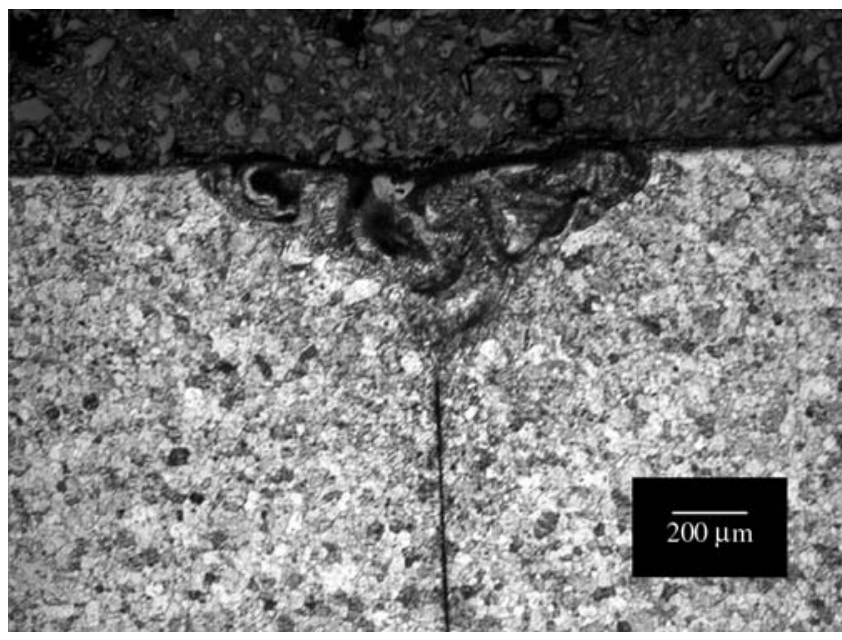

(a)

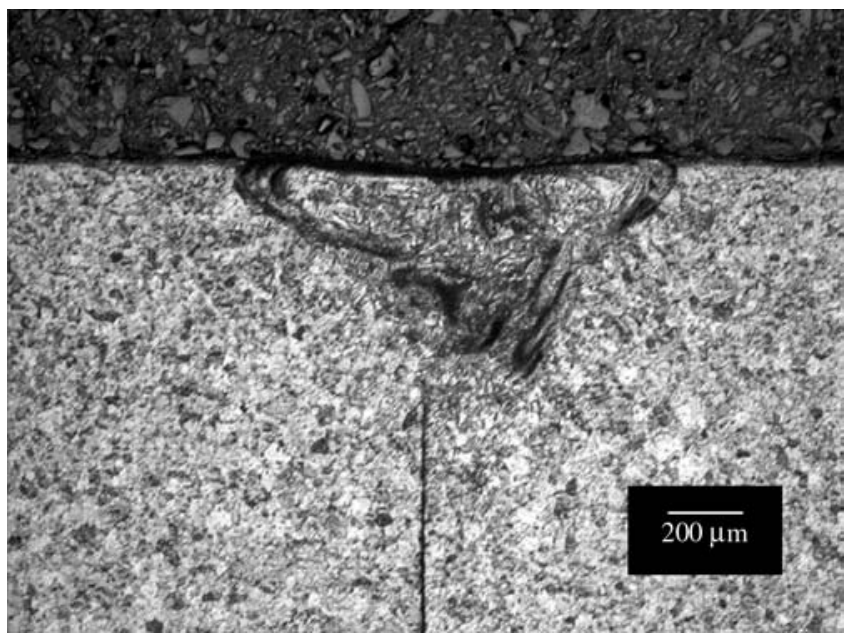

(b)

Figure 7. a) Transversal cut of the welding under a) normal; and b) optimized conditions. The energy is decreased by $30 \%$ in comparison with the conditions used to produce the Figure 3.

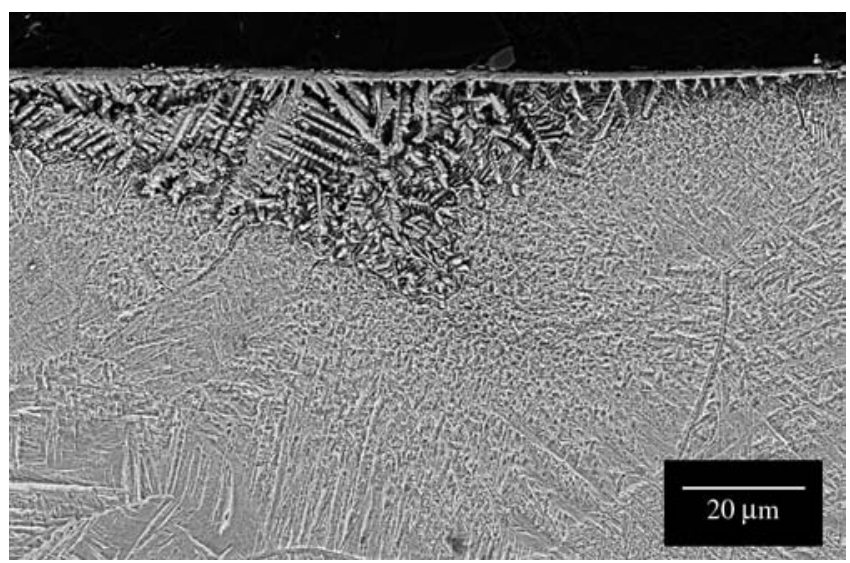

Figure 8. Detail of TiN dendrites near to the materials surface.

This can be seen as the TiN phase, which were presented dark in the micrographs, were reduced in the PS compared to the normal conditions. This is better seen in Figure 7, where the melt pool volume
Table 3. Vicker's microhardness values (HV100 g).

\begin{tabular}{lcc}
\hline \multicolumn{1}{c}{ Region } & Normal & Optimized \\
\hline (1) Top & 455 & 433 \\
(2) Center & 296 & 412 \\
(3) Root & 283 & 333 \\
(4) Titanium base & 176 & 188 \\
\hline
\end{tabular}

is reduced. The nitrogen and microhardness distributions, Tables 1 and 2, also indicate that the nitrogen is better distributed with the pulse shaping.

After this short pulse, a long pulse of $8 \mathrm{~ms}$ was imposed to the surface. This pulse is principally similar to the long pulse of $10 \mathrm{~ms}$ which is produced under normal conditions and is responsible for the penetration. This period is characterized by the presence of a keyhole and the transfer of TiN dissociated nitrogen to regions further away from the top.

Finally, a quenching slope was imposed by decreasing the energy at the end of the pulse, generating a lower thermal gradient and finally leading to reduced residual stresses. The quenching slope had 4 ms length and contributes to increase the pulse length by $20 \%$, also contributing to an improved nitrogen distribution into the weld.

Figure 6 shows that the solute transfer is mainly controlled by a convection flux that runs from the center of the weld to the boarders, thus dropping and raising again in the center of melt pool. The liquid is propelled from hot central regions where surface tension is low to colder regions where surface tension is high. Under normal conditions, these currents are confined to the surface, Figure 3a, which leads to a high concentration of nitride phase and ultimately to cracking. Both nitrogen concentration and hardness values seem to confirm this hypothesis. These same factors indicate that PS effectively promotes better distribution of nitrogen and enhanced weldability.

It was verified that the zones which receive more nitrogen also presents high amounts of fine martensite. This effect is associated to the stabilization of $\alpha$-phase (HCP). When the $\beta$-phase (BCC) of high-temperature is rapidly quenched, it transforms to the $\alpha$-phase though a martensitic reaction ${ }^{10}$. High nitrogen concentration increases the Ms value (martensite start temperature), and consequently more martensite is transformed.

The elevated hardness observed in both normal pulse welding condition and pulse-shaping condition indicates poor mechanical properties of the joint. Even though this aspect is of importance for weld performance, the mechanical behavior of the welding, such as ductility and fracture strength, is not evaluated here. The sequence of this work will focus on these particular factors, including the effect of pulse shaping on the ductility and on the stress-strain response of the welds. Additionally, any further study must consider weld tracks composed by overlapped pulses.

\section{Conclusions}

An improved weldability of titanium nitride coated titanium was obtained by a pulse-shaping mediated laser process. The energy distribution of the laser beam was divided in three consecutive steps: a high power short pulse where the titanium nitride was dissociated, a long pulse which allowed thermal penetration and a quenching slope to decrease the residual stresses. The pulse-shaping process has shown effectively transfer of nitrogen to the melt pool and decreased cracking on the top part of the seam. Further work concerning the mechanics properties of the join, such as ductility and fracture strength, is under way. 


\section{Acknowledgments}

The author thanks a fellowship from Ecole Polytechnique Fédérale de Lausanne (EPFL-Switzerland) and Laboratoire de simulation des matériaux. Thanks are also due to the company Brasimet Com. Ind. SA for the coatings and to Eng. J.D. Wagnière for assistance in laser processing. This project has been financed by the Fundação de Amparo à Pesquisa do Estado de São Paulo (Grant 02/10009-0).

\section{References}

1. Williams JC, Starke Jr. EA. Progress in structural materials for aerospace systems. Acta Materialia. 2003; 51:5775-5799.

2. Boyer RR. On the use of titanium in the aerospace industry. Mater. Sci. Eng. 1996; A213:106-114.

3. Mendez PF, Eagar TW. Welding processes for aeronautics. Adv. Mater. Proc. 2001; 5:39-43.

4. Mucha A, Braun M. Required parameters for optimal wear performance of nitrogen implanted titanium and Ti-6AI-4V. Surf. Coat. Techn.1992; 50:135-139.
5. Avni R, Spalvins T. Nitriding mechanisms in Ar-N2, Ar-N2-H2 and ArNH3 mixtures in D.C. Glow discharges at low pressures (less than 10 Torr). Mater. Sci. Eng. 1987; 95:237-246.

6. Rickerby DS, Bull SJ. Engineering with surface coatings: The role of coating microstructure. Surf. Coat. Techn.1989; 39:315-328.

7. Schubert E, Klassen M, Zerner I, Walz G, Sepold G. J. Light-weight structures produced by laser beam joining for future applications in automobile and aerospace industry. Mater. Proc. Techn. 2001; 115:2-8.

8. Michaud EJ, Kerr HW, Weckman DC. Temporal pulse shaping and solidification cracking in laser welded Al-Cu alloys. In: Smartt HB, Johnson JA, David SA. (editors). Proceedings of the 4th International Conference on Trends in Welding Research; 1995 Jun 5-7; Gatlinburg, Tennesse, USA; 1995. p. 1-6.

9. Drezet JM, Bezencon C, Mokadem S. Computer simulation of Maragoni flux during laser remelting, Internal report Calcom Co. Ltd., Lausanne, Switzerland: Calcom ESI Ltd.; 2002. 12 p.

10. Smith WF. Titanium alloys. In: Smith WF (editor). Structure and Properties of Engineering Alloys. London: McGraw-Hill Publishing Co.; 1981. p. 101-121. 